\title{
KELAYAKAN USAHATANI BAYAM (Amaranthus spp) MEDIA PASIR DESA ABUMBUN JAYA KECAMATAN SUNGAI TABUK KABUPATEN BANJAR
}

(The Feasibility Analysis of Spinach Farming (Amaranthus spp) Sand-Soil Media in Abumbun Jaya Village Sungai Tabuk Subdistrict Banjar Regency”

\author{
Fitri Mahyudi ${ }^{1}$, dan Husinsyah ${ }^{2}$ \\ ${ }^{1,2}$ Program Studi Agribisnis Fakultas Pertanian Universitas Achmad Yani Banjarmasin \\ Jl. A. Yani KM 32,5 Banjarbaru \\ Email:fitri.mahyudi@yahoo.co.id, husinactivities@ gmail.com
}

Article Submitted: 01-03-2020

Article Accepted: 13-09-2020

\begin{abstract}
This research aims to know technically about effort management spinach farming evaluated from the technical aspect in Abumbun Jaya Village Sungai Tabuk Subdistrict Banjarbaru City South Kalimantan Province and to know about cost, acceptance, revenue, and spinach farming Feasibility. According to the result of seen from technical management spinach farming still relative modestly, this is seen from farm processing until the conservancy. Production obtained from 25 spinach farmer responder with a wide mean equal to $352.236,45 \mathrm{~kg} /$ farmer. Productivity $1.030,64 \mathrm{~kg}$. Total Revenue with mean Rp. 5.668.520 per farmer. RCR Value spinach farming 1.67 competent so that to be feasible (RCR $>1)$.
\end{abstract}

Keywords: Spinach, price, cost, revenue, feasibility analysis

\section{PENDAHULUAN}

Sejalan dengan visi dan misi pembangunan pertanian dewasa ini, dimana program utamanya adalah peningkatan ketahanan pangan dan pengembangan agribisnis, maka mendukung program tersebut beberapa komoditas sayuran dikembangkan adalah bayam, kangkung, sawi, dan lainnya. Hal tersebut dimaksudkan dalam rangka pencapaian swasembada sayuran untuk memenuhi kebutuhan sayuran di pasar terdekat dan untuk menambah penghasilan para petani. Produksi sayuran Dikabupaten Banjar masih tergolong rendah karena ditandai dengan banyaknya sayuran impor yang masih memenuhi pasar yang ada.

Komoditas Horitikultura merupakan komoditas yang dikonsumsi setiap hari, sehingga perlu untuk dikembangkan. Perlu dikembangkannya komoditas-komoditas Hortikultura karena komoditas ini memiliki nilai Ekonomis yang tinggi seperti halnya pada bayammaka apabila dikembangkan dalam suatu sistem usahatani yang komersial dapat meningkatkan pendapatan petani. Pertumbuhan bayam tidak mengenal musim, sehingga mudah diperoleh setiap saat (Suratiyah, 2006). Varietas atau jenisnya juga cukup banyak. Keanekaragaman varietas tersebut diperoleh melalui kegiatan pemuliaan tanaman. Dengan pemuliaan tanaman,dihasilkan banyak varietas yang memiliki keunggulan, seperti tahan terhadap hama dan penyakit tertentu atau tahan terhadap cuaca atau lingkungan yang tidak mendukung (Soenoeadji, 2001).

Golongan atau group bayam (Amaranthus spp) menurut keluarga Amaranthaceae memiliki sekitar 60 genera, 
terbagi dalam sekitar 800 spesies bayam. Dalam kenyataan di lapangan, penggolongan jenis bayam dibedakan atas 2 macam, yaitu ( Rahmat Rukmana, 1994 ). Jenis bayam budidaya dibedakan 2 macam, yaitu:

1. Bayam sekul alias bayam putih (A. tricolor L.).

Ciri-ciri bayam cabut adalah memiliki batang berwarna kemerah-merahan atau hijau Bayam cabut atau keputih-putihan, dan memilki bunga yang keluar dari ketiak cabang. Bayam cabut yang batangnya merah disebut bayam merah, sedangkan yang batangnya putih disebut bayam putih.

2. Bayam tahun, bayam skop atau bayam kakap (A. hybridus L.).

Ciri-ciri bayam ini adalah memiliki daun lebar-lebar, yang dibedakan atas 2 spesies yaitu:

a. A. hybridus caudatus L., memiliki daun agak panjang dengan ujung runcing, berwarna hijau kemerahmerahan atau merah tua, dan bunganya tersusun dalam rangkaian panjang terkumpul pada ujung batang.

b. A. hibridus paniculatus L., mempunyai dasar daun yang lebar sekali, berwarna hijau, rangkaian bunga panjang tersusun secara teratur

Media tanah pasir sudah mulai dikembangkan petani sayuran termasuk bayam, karena pasir adalah jenis tanah yang sangat porous dan miskin unsur hara sehingga penggunaan lahan jenis ini untuk keperluan budidaya tanaman harus dilakukan penambahan pupuk dan bahan lainnya sebagai pengikat air dan sumber hara tanah bagi tanaman (Kartika Kusumawati, dkk. 2015)

Kabupaten Banjar kegiatan pembangunan ekonominya diprioritaskan bidang pertanian. Pada sektor pertanian, salah satu yang dikembangkan masyarakat setempat berupa tanaman pangan, yang meliputi padi, palawija, dan hortikultura. Komoditas hortikultura yang dikembangkan masyarakat atau petani di Kabupaten Banjar, diantaranya adalah tanaman bayam. Permasalahan yang dihadapi petani bayam diantaranya adalah masih mininya modal yang dimiliki petani sehingga dalam pemanfaatan sarana produksi belum maksimal, seringnya hama penyakit ynag menyerang tanaman dan berfluktuasinya harga komoditi bayam serta cuaca yang tidak mendukung.

Desa Abumbun Jaya merupakan salah satu dari 20 desa dan 1 kelurahan yang ada di Kecamatan Sungai Tabuk memiliki luas wilayah 707,75 Ha.. Daerah ini merupakan daratan rendah yang sebagian besar lahan kosong dan cocok untuk usahatani hortikultura, khususnya bayam. Mengingat lahan yang ada cukup luas untuk dikembangkan lagi, diikuti dengan peningkatan produksi melalui berbagai terobosan teknologi, penyebaran varitas unggul dan perbaikan efesiensi usahatani, maka diharapkan produksi bayam akan lebih meningkat. Untuk komoditi yang banyak diusahakan adalah tanaman bayam dengan mengunakan varietas tantina. Petani di Desa Abumbun Jaya tergolong petani tradisional dan masih menggunakan alat-alat yang sederhana, dan petani belum bisa memperhitungkan mengenai biaya yang dikeluarkan, sehingga petani tidak dapat menaikkan pendapatan keluarga.

Permasalahan yang dihadapi oleh petani bayam di Desa Abumbun Jaya Kecamatan Sungai Tabuk Kabupaten Banjar Provinsi Kalimantan Selatan yaitu datangnya hama dan penyakit pada tanaman bayam, harga jual yang tidak tetap. Masalah diatas inilah peneliti ingin melihat dan mengamati keberadaan serta kegiatan usahatani ini, baik dari segi teknis dan dari segi ekonomis. Dalam pelaksanaannya nanti akan terlihat sejauh mana kegiatan usahatani bayam akan memberikan gambaran berapa besarnya biaya, penerimaan, keuntungan dan kelayakan usahatani bayam. 


\section{METODE PENELITIAN}

Penelitian ini dilaksanakan di Desa Abumbun Jaya Kecamatan Sungai Tabuk Kabupaten Banjar Kalimantan Selatan selama 3 bulan mulai bulan Juni 2020 September 2020, yaitu dari tahapan persiapan sampai menyusun laporan. Data yang diperoleh kemudian diolah dengamn metode Simple Random Sampling yaitu dari 50 populasi petani dirandom $50 \%$ menjadi 25 petani sampel selanjutnya dianalisis secara deskriptif, dan dilakukan analisis finansial (M. Subana dan Sudrajat, 2005).

Menurut Soekartawi, (2006), biaya total, yaitu keseluruhan jumlah biaya produksi yang dikeluarkan. Secara matematis biaya total dapat dirumuskan sebagai berikut:

$$
\mathbf{T C}=\mathbf{T F C}+\mathbf{T V C}
$$

Keterangan

$$
\begin{aligned}
\text { TC }(\text { Total Cost }) & =\text { Biaya Total } \\
& (\mathrm{Rp}) \\
\text { TFC }(\text { Total Fixed Cost }) & = \\
& \text { Total Biaya } \\
& \text { Tetap }(\mathrm{Rp})
\end{aligned}
$$

TVC $($ Total Variable Cost $)=$ Total Biaya

$$
\text { Variabel (Rp) }
$$

Menurut Ronny (2010), penerimaan total secara langsung ditentukan oleh jumlah produk yang terjual dan yang diterima. Secara matematis penerimaan total dapat dirumuskan sebagai berikut:

$$
\mathbf{T R}=\mathbf{P} \times \mathbf{Q}
$$

Keterangan :

$$
\begin{array}{ll}
\mathrm{TR}(\text { Total Revenue }) & =\text { Penerimaan total } \\
& (\mathrm{Rp}) \\
\mathrm{P}(\text { Price }) & = \\
\mathrm{Q}(\text { Quarga produk }(\mathrm{Rp}) & =\operatorname{Jumlah} \operatorname{produk}(\mathrm{Kg})
\end{array}
$$

Menurut Syarifuddin A. Kasim (1995), untuk menentukan tingkat pendapatan maka dianalisis secara tabulasi sederhana dengan menggunakan rumusan sebagai berikut :

$$
\mathbf{I}=\mathbf{T R}-\mathbf{T V C}
$$

Keterangan :

I $\quad($ Total Revenue $)=$ Pendapatan Total

TR $($ Total Revenue $)=$ Penerimaan Total

$$
\text { (Rp) }
$$

TVC $($ Total Variable Cost $)=$ Biaya

Variabel Total (Rp)

Adapun Kelayakan usaha secara ekonomis dapat dinilai dengan persamaan sebagai berikut (Kasmir dan Jakfar, 2008).

$R / C$ Ratio $=\frac{\text { TR }}{\text { TC }}$

Keterangan :

TR $($ Total Revenue $)=$ Penerimaan Total (Rp)

TC $($ Total Cost $)=$ Biaya Total $(\mathrm{Rp})$

R/C Ratio > 1 : usaha dikatakan layak

$\mathrm{R} / \mathrm{C}$ Ratio $=1$ : usaha dikatakan berada di titik impas

R/C Ratio $<1$ : usaha dikatakan tidak layak

\section{HASIL DAN PEMBAHASAN}

\section{Aspek Teknik Usahatani Bayam (Amaranthus spp)}

\section{Benih}

Salah faktor utama yang mendukung keberhasilan usaha peningkatan produksi adalah penggunaan varietas yang berdaya hasil tinggi dan tahan terhadap serangan hama dengan petanian penyakit. Dari hasil wawancara dengan petani responden ternyata petani menanam varietas local, pemilihan benih untuk bibit bertanam dilakukan dengan cara menyeleksi kualitas bibit yang ada dipasaran.

\section{Persiapan Lahan}

Pada umumnya sistem pengolahan tanah yang dilakukan petani dengan cara membersihkan lahan dari sisa tanaman dan rumput secara manual atau dengan menggunakan tenaga manusia serta dengan penggemburan. Pembersihan tanah pada lahan pekarangan yang belum pernah dilakukan budidaya, rumput yang telah dibersikan ditimbun didalam tanah.

\section{Persemaian}

Tempat yang dilakukan dalam pesemaian disediakan secara khusus untuk digunakan sebagai tempat penanaman sementara, untuk mendapatkan bibit 
bermutu sehingga budidaya tanaman bayam (amaranthus spp) bisa memperoleh hasil yang maksimal. Pembibitan yang digunakan dalam Usaha Budidaya bayam (amaranthus spp) adalah dengan cara disemai.

\section{Penanaman}

Benih yang memenuhi persyaratan untuk ditanam di lahan permanen yang sudah berumur 2 minggu. Adapun dalam penanaman benih yang sudah siap ditanam dilakukan secara berlahan.

\section{Perawatan Tanaman}

Adalah suatu perlakuan khusus pada tanaman agar bisa tumbuh dan berkembang sesuai yang diharapkan. Adapun perawatan meliputi :

\section{a. Penyiraman}

Penyiraman dilakukan memenuhi kebutuhan tanaman akan air sehingga tidak mengalami kekeringan yang dapat mengakibatkan tanaman layu dan mati, selain itu juga untuk mengganti air yang hilang diserap tanaman atau karena penguapan. Penyiraman dilakukan dua kali sehari yaitu pagi jam 07.00 dan sore jam 17.00 wita akan tetapi jika turun hujan penyiraman tidak dilakukan.

b. Penjarangan

Penjarangan dilakukan 2 minggu setelah penanaman. Caranya dengan mencabut tanaman yang tumbuh terlalu rapat.

c. Penyulaman

Penggantian tanaman dengan tanaman baru. Caranya yaitu tanaman yang mati atau terserang hama dan penyakit diganti dengan tanaman yang baru yaitu dengan menambahkan bibit yang baru

d. Pemupukan susulan

Pemupukan susulan perlu dilakukan untuk menambah unsur hara yang dibutuhkan. Pemupukan dilakukan dengan cara ditebarkan di sekitar tanaman, pupuk yang digunakan yaitu pupuk urea dan NPK dengan dosis sekali tebar $2 \mathrm{~kg}-3 \mathrm{~kg}$.

e. Penyiangan

Penyiangan dilakukan 2-4 kali selama masa pertanaman bayam (amaranthus spp), disesuaikan dengan kondisi keberadaan gulma pada bedeng penanaman. penyiangan dilakukan 1 atau 2 minggu setelah penanaman.Yaitu mencabut rumput yang tumbuh di sekitar tanaman, dengan tujuan agar makanan yang diperlukan oleh tanaman tidak terbagi-bagi sehingga proses pertumbuhan dapat maksimal dan dilakukan pada pagi hari.

\section{Panen}

Panen bayam ketika berumur sekitar 40 hari setelah tanam dipanen dengan cara mencabut seluruh tanaman, pemanenan dilakukan pada pagi hari atau sore hari apabila ada permintaan dari luar daerah.

Tanaman bayam sangat memerlukan tanah yang gembur, subur dan kaya unsur hara dimana untuk mempertahankan kelembaban tanah dapat diberikan mulsa sekaligus menekan pertumbuhan gulma. Pemberian pupuk organic (kescing) dapat meningkatkan pertumbuhan bayam dengan dosis 5 gram $/ \mathrm{kg}$ tanah $\left(\mathrm{k}_{2}\right)$ yang berpengaruh terhadap pertumbuhan, jumlah daun, berat kering tajuk dan pertumbuhan akar (Tia Setiawati dkk, 2018).

\section{Analisis Usahatani Bayam (amaranthus spp)}

Komponen biaya yang dihitung dan dianalisis pada usahatani bayam selama 1 (satu) kali musim tanam, yaitu 1 (satu) bulan, meliputi biaya sarana produksi, biaya alat perlengkapan dan pajak lahan serta biaya tenaga kerja.

\section{Biaya sarana Produksi}

Untuk lebih jelasnya mengenai biaya sarana produksi pada usahatani bayam dapat dilihat pada Tabel 1 berikut. 
Tabel 1. Rata-rata Biaya Sarana Produksi Usahatani Bayam di Desa Abumbun Jaya.

\begin{tabular}{clcc}
\hline No & \multicolumn{1}{c}{ Uraian } & Biaya (Rp) & Persentasi (\%) \\
\hline 1 & Benih & 284.700 & 27,89 \\
2 & Pupuk Urea & 24.200 & 2,37 \\
3 & Pupuk NPK & 102.060 & 9,99 \\
4 & Pupuk Kandang & 503.818 & 49,34 \\
5 & Gramoxone & 106.250 & 10,41 \\
\hline & Jumlah & 1.021 .028 & 100,0 \\
\hline
\end{tabular}

Sumber : Hasil Pengolahan Data Primer Tahun 2020

Biaya sarana produksi yang dikeluarkan dihitung dengan mengalikan jumlah input produksi yang digunakan dengan harga masing-masing input. Biaya sarana produksi meliputi keperluan benih rata-rata sebesar Rp. $284.700,00$ per petani dengan jumlah biaya sarana produksi terbesar adalah pupuk kandang sebesar Rp. 503,818 (49,34 \%) dan biaya terendah adalah biaya Pupuk Urea yaitu Rp. 24.200 $(2,37 \%)$.

\section{Biaya Penyusutan Alat}

Tabel 2. Rata-rata Biaya Penyusutan Alat Pada Usahatani Bayam di Desa Abumbun Jaya Kecamatan Sungai Tabuk

\begin{tabular}{clcc}
\hline No & \multicolumn{1}{c}{ Uraian } & Biaya (Rp) & Persentasi $(\%)$ \\
\hline 1 & Parang & $2.604,17$ & 12,16 \\
2 & Cangkul & $3.125,00$ & 14,59 \\
3 & Ceret Air & $2.083,33$ & 9.73 \\
4 & Hand Sprayer & $8.333,33$ & 38,92 \\
5 & Karung & $5.266,71$ & 24,60 \\
\hline & Jumlah & $21.412,54$ & 100,00 \\
\hline
\end{tabular}

Sumber : Pengolahan Data Primer (2020)

Berdasarkan data pada Tabel 2 diketahui biaya penyusutan alat terbesar pada penggunaan handsprayer yaitu sebesar Rp. 8.333,33 per petani $(38,92 \%)$ sedangkan yang terkecil pengunaan pada ceret air yaitu Rp. $2.083,33$ per petani $(9.73$ $\%)$.

\section{Biaya Tenaga Kerja Luar Keluarga}

Dalam kegiatan usahatani bayam yang dilaksanakan petani selama satu kali musim tanam, tenaga kerja luar keluarga
Sehubungan dengan berkurangnya nilai pakai alat-alat produksi pertanian, maka dapat diadakan perhitungan biaya penyusutan alat-alat tahan lama yang mengandung sejumlah nilai pakai yang harus diperhitungkan setiap tahunnya. Biaya penyusutan ini tergantung pada nilai alat saat pembeliaan, usia ekonomis alat, nilai sisa setelah habis jangka ekonomis tersebut (dalam hal ini dianggap nol) dan masa kerja efektif alat pada usahatani bayam. 
Tabel 3. Biaya Eksplisit Rata-rata yang dikeluarkan pada Usahatani Bayam di Desa Abumbun Jaya.

\begin{tabular}{llrc}
\hline No & \multicolumn{1}{c}{ Uraian } & Biaya (Rp) & Persentasi (\%) \\
\hline 1 & Penyusutan alat & $21.412,54$ & 0,63 \\
2 & Saprodi & $1.021 .028,00$ & 30,13 \\
3 & TKLK & $2.346 .119,88$ & 69,24 \\
\hline & Jumlah & $3.388 .559,90$ & 100,00
\end{tabular}

Sumber : Pengolahan Data Primer (2020)

Dari Tabel 3 diketahui, penggunaan biaya tertingi dan terendah pada petani yaitu biaya tertinggi pada tenaga kerja dalam keluarga yaitu sebesar Rp. 2.346.119,88 $(69,24 \%)$ sedangkan biaya penggunaan terandah pada penyusutan alat yaitu sebesar Rp. 21.412,54 (0,63\%).

\section{Penerimaan}

Penerimaan adalah perkalian antara total produksi dengan harga yang berlaku pada saat itu, dari hasil wawancara dengan seluruh petani responden diperoleh total rata-rata produksinya adalah sebesar $1.030,64 \mathrm{Kg} /$ petani dengan harga bayam Rp. $5.500 / \mathrm{kg}$. Sehingga total penerimaan ratarata adalah Rp. 5.668.520/petani.

\section{Pendapatan}

Pendapatan adalah hasil pengurangan antara total penerimaan dengan total biaya eksplisit yang dikeluarkan petani dalam satu musim tanam. pendapatan yang di peroleh petani dalam satu musim tanam adalah Ratarata sebesar Rp. 2.279.960,10/petani.
Pendapatan masih dapat ditingkatkan dengan mempelajari situasi pasar dan system pemasaran agar memperoleh harga yang memadai. Agar tingkat pendapatan meningkat perlu adanya peningkatan peningkatan efesiensi biaya dan peningkatan penerimaan (TR) melalui peningkatan hasil produksi. Hal ini bisa dilaksanakan apabila petani mengetahui penggunaan hubungan antara input dan output. Semakin optimal penggunaan input produksi diharapkan output bisa lebih maksimal.

\section{Kelayakan}

Revenue cost ratio (RCR) adalah ratio yang digunakan untuk melihat keuntungan relatif yang akan didapatkan dalam sebuah usaha. Sebuah usaha layak untuk dijalankan apabila nilai RCR yang didapatkan lebih besar daripada 1, sebaliknya bila usaha layak untuk dijalankan apabila nilai RCR yang didapatkan kurang dari pada nilai 1 .

Tabel 4. Penerimaan, Pendapatan dan Kelayakan (RCR) Usahatani Bayam Media Tanah-Pasir di Desa Abumbun Jaya Kecamatan Sungai Tabuk Kabupaten Banjar

\begin{tabular}{clc}
\hline No & Uraian & $\begin{array}{c}\text { Nilai } \\
\text { (Rp/Petani) }\end{array}$ \\
\hline 1 & Penerimaan & $5.668 .520,00$ \\
2 & Biaya Ekplisit & $3.388 .559,90$ \\
3 & Pendapatan & $2.279 .960,10$ \\
4 & Kelayakan (RCR) & 1,67 \\
\hline
\end{tabular}

Sumber : Pengolahan Data Primer (2020)

Nilai RCR didapat dengan membandingkan nilai penerimaan dengan total biaya usahatani bayam. Untuk usahatani bayam didapat total penerimaan rata-rata adalah 5.668.520/petani dan biaya ekplisit total yang digunakan dalam 
usahatani bayam adalah rata-rata $\mathrm{Rp}$. 3.388.559,90/petani. Sehingga didapat nilai RCR adalah 1.67. Nilai RCR usahatani bayam yang lebih besar dari 1 dapat disimpulkan usahatani bayam di Desa Abumbun Jaya layak untuk dijalankan. Untuk lebih jelasnya tentang penerimaan, pendapatan dan Kelayakan (RCR) usahatani bayam media tanah-pasir dapat dilihat pada Tabel 4.

Pada penelitian analisis pendapatan dan kelayakan ussahatani bayam cabut (Amaranthus tricolor) secara monokultur di lahan pekarangan dengan jumlah sampel 43 petani di Desa Babad sari Kecamatan Kotawinangun Kabupaten Kebumen Provinsi Jawa Tengah nilai kelayakan usaha yaitu R/C ratio sebesar 7,71 (Dyah Utami, 2017).

Pada penelitian analisis usahatani bayam yang merupakan studi kasus di Kelurahan Sasa Kecamatan Ternate Selatan Kota Ternate provinsi Maluku Utara menunjukkan bahwa pendapatan usahatani bayam sebesar Rp. 24.095.000 dengan nilai $\mathrm{B} / \mathrm{C}$ ratio sebesar 2,4687. Dari angka tersebut usahatani bayam layak diusahakan dengan nilai $\mathrm{B} / \mathrm{C}$ ratio $>1$. (Haryati $\mathrm{La}$ Kamisi, 2018).

Pada penelitian analisis pendapatan dan kelayakan usahatani kelayakan sayuran organic di CV. Rahayu Desa Sidera Kecamatan Sigi Biromaru Kabupaten Sigi Provinsi Sulawesi Tengah menunjukkan bahwa pendapatan bayam sebesar Rp. $3.964 .500 / 150 \mathrm{~m} 2$ dengan nilai $\mathrm{R} / \mathrm{C}$ ratio sebesar 2,6. Dari angka tersebut usahatani bayam layak diusahakan dengan nilai $\mathrm{B} / \mathrm{C}$ ratio > 1 (Nidaul, Sayaifudin Nasrun, Irmawaty, 2018).

Hasil penelitian mengenai evaluasi kelayakan teknis yang dilakukan berdasarkan parameter keseragaman debit aliran, keseragaman konduktivitas listrik, keseragaman derajat keasaman, kedalaman aliran, dan bobot tanaman, menghasilkan nilai keseragaman yang secara umum mendekati $90 \%$ sehingga teknik hidroponik dapat diterapkan. Namun secara khusus nilai keseragaman masih kurang baik pada kedalaman aliran dan bobot tanaman, hal ini disebabkan karena terdapatnya lipatan pada terpal pelapis bed sehingga permukaan bed menjadi tidak ata.Pada kelayakan finansial, usaha yang dilakukan oleh PT. Joy Farm pada

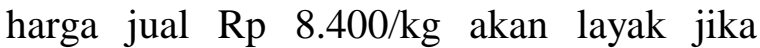
produksi yang dilakukan sesuai target yaitu $17 \mathrm{~kg} / \mathrm{bed}$. Namun pada kenyataanya target yang diharapkan tidak tercapai sehingga usaha menjadi tidak layak. Untuk dapat melanjutkan usahanya maka diperlukan alternatif seperti melakukan negosiasi ulang terhadap pihak mitra mengenai harga jual, sehingga harga jual yang digunakan menjadi $\mathrm{Rp} 16.800 / \mathrm{kg}$ atau sekurang-kurangnya Rp 14.200/kg. Harga jual tersebut memberikan kelayakan pada PT.Joy Farm dalam melanjutkan usahanya. Di samping itu PT Joy Farm juga perlu menekan biaya produksi melalui penggunaan nutrisi sesuai standar dan mencari alternatif pemasaran lain (Prasetya, Andika, 2009).

Hasil penelitian dan pembahasan menyimpulan bahwa; 1) Keadaan usahatani bayam masih ada yang bersifat tradisional dengan pola kepemilikan lahan milik sendiri, sewa, bagi hasil dan pola tanam yang belum teratur masih sesuai dengan keinginan petani namun sudah mengadopsi teknologi dengan baik; 2) Penggunaan faktor produksi usahatani bayam di daerah penelitian masih tergolong rendah dengan rata-rata luas lahan 4,20 rante, tenaga kerja 34,34 HKSP, pupuk 2.192,09 kg, pestisida $1,22 \mathrm{~kg} / \mathrm{ltr}$ dan benih $2,26 \mathrm{~kg} ; 3$ ) Rata-rata penggunaan biaya usahatani bayam di daerah penelitian adalah $\mathrm{Rp} 2.988 .114,86$ rata-rata penerimaan $\mathrm{Rp}$. 10.446.000,00 dan rata-rata pendapatan usahatani bayam sebesar Rp. 7.457.885,14 dengan rata-rata luas lahan 4,20 Rante; 4) Usahatani bayam layak untuk diusahakan dengan R/C Ratio rata-rata sebesar 3,51; 5) Break Even Point dalam unit usahatani bayam di daerah 
penelitian sebesar 285,39 ikat dengan luas lahan rata-rata 4,20 Rante; 6) Break Even Point dalam rupiah usahatani bayam di daerah penelitian sebesar Rp. 336.090,74 dengan luas lahan rata-rata 4,20 Rante; 7) Price Break Even usahatani bayam di daerah penelitian sebesar Rp. 345,89 (Surya Dharma, 2014).

Hasil dari penelitian pendapatan usahatani dari kelompok tani Jaya Desa Ciaruteum Ilir sebesar Rp. 3.649.993/Ha/tahun/petani dan usahatani sayuran ini dinilai layak untuk dijalankan dan berprospek bagus untuk dikembangkan. Saran yang bisa diajukan setelah dilakukan penelitian ini adalah: 1) Data hasil penelitian menunjukkan bahwa usahatani sayuran di kelompok Tani Jaya ini sangat menguntungkan dan efektif, hal tersebut juga menunjukkan bahwa usahatani sayuran ini mempunyai prospek yang bagus untuk dikembangkan dengan cara penambahan luas area tanam. Dengan bertambahnya luas areal serta pengelolaan yang bagus akan meningkatkan produksi dan diikuti dengan bertambahnya pendapatan petani. 2) Disarankan ada pelatihan manajemen yang baik terhadap para anggota kelompok tani. Baik itu pelatihan mengenai teknis usahatani maupun non teknis seperti pelatihan menganalisis usahatani dengan baik (Dodi Normansyah, Siti Rochaeni, Armaeni Dwi Humaerah , 2014).

Bayam Jepang (Spinacia oleracea Linn) atau Horenso merupakan komoditas sayuran eksklusif Jepang sejenis bayam yang banyak diminati karena rasanya yang enak serta kaya akan zat gizi yang baik bagi kesehatan. Restoran Jepang yang banyak didirikan di kota-kota besar menjadi prospek pasar untuk sayuran bayam Jepang, sehingga diperlukan analisis usahatani bayam Jepang untuk mengetahui keuntungan yang dihasilkan. Tujuan penulisan karya ilmiah untuk menjelaskan kegiatan usahatani bayam Jepang, menganalisis biaya produksi, penerimaan, dan keuntungan usahatani bayam Jepang. Metode analisis data yang digunakan adalah deskriptif kuantitatif. Hasil dan pembahasan diperoleh bahwa kegiatan usahatani bayam Jepang yaitu pra tanam, penanaman, pemeliharaan, dan panen, total biaya produksi seluas $506 \mathrm{~m} 2$ sebesar Rp 6.653.771, penerimaan sebesar Rp 9.975.000 dan keuntungan sebesar $\mathrm{Rp}$ 3.321.229, $\mathrm{R} / \mathrm{C}$ ratio usahatani bayam Jepang adalah 1,49 dan $\mathrm{B} / \mathrm{C}$ ratio adalah 0,49 . Usahatani bayam Jepang mencapai titik impas saat dihasilkan $194 \mathrm{~kg}$ sayuran bayam Jepang layak jual atau penerimaan Rp 2.909.944 (Eka Febrianty, dkk. 2017).

Petani di Desa Waiheru memiliki beberapa keterbatasan dalam hal faktor produksi seperti kepemilikan lahan (bukan milik sendiri dan tergolong sempit), menggunakan tenga kerja luar keluarga sehingga membutuhkan upah, biaya pupuk tinggi, dan biaya produksi lainnya serta harga sayuran yang berfluktuasi. Penelitian ini bertujuan untuk mengetahui pendapatan yang diperoleh petani dan kelayakan usahatani sayuran. Metode pengambilan sampel yang digunakan adalah stratified random sampling. Selanjutnya data dianalisis dengan menggunakan analisis kuantitatif. Hasil penelitian menunjukkan bahwa pendapatan petani sayuran adalah per tahun sebesar Rp.45.686.640,- untuk lahan sempit, Rp.48.332.500,- untuk lahan sedang, dan Rp.51.778.775,- untuk lahan luas. Usahatani sayuran layak dikembangkan karena menguntungkan dengan nilai BCR 1,49 (Sibastianus Palaudi , 2015).

Usaha sayuran hidroponik di Kota Tangerang Selatan adalah Kebun Koe Hidroponik CV. Kelapa Agro Lestari yang memfokuskan komoditas sayuran oriental dengan metode hidroponik (Nutrient Film Technique) dan tanpa naungan rumah kaca dalam proses budidaya hidroponik. Tujuan penelitian ini adalah menganalisis keuntungan yang diperoleh dari budidaya sayuran oriental dan mengukur tingkat efisiensi usahatani sayuran oriental dengan sistem hidroponik NFT tanpa naungan rumah kaca berdasarkan $\mathrm{R} / \mathrm{C}$ ratio pada 
Kebun Koe Hidroponik di Desa Cipayung, Kota Tangerang Selatan, Provinsi Banten. . Penelitian ini dilakukan dari Mei hingga Juli 2018. Jenis penelitian ini adalah penelitian deskriptif kuantitatif. Metode analisis data yang digunakan dalam penelitian ini adalah analisis struktur biaya, analisis profit dan efisiensi usahatani berdasarkan $\mathrm{R} / \mathrm{C}$ ratio. Hasil penelitian menunjukkan bahwa meskipun Kebun Kapur Hidroponik CV Kelapa Agro Lestari memproduksi jenis sayuran yang sama dengan sayuran konvensional seperti kangkung, caysim dan pakcoy, usaha tetap menguntungkan dan efisien. Berdasarkan analisis rasio $\mathrm{R} / \mathrm{C}$ sayuran oriental hidroponik di Hydroponic Koe Garden yang efisien untuk dijalankan ( $\mathrm{R} / \mathrm{C}$ ratio> 1). $\mathrm{R} / \mathrm{C}$ ratio untuk komoditas bayam, caysim dan pakcoy masing-masing adalah 1,17, 1,07 dan 1,22. Komoditas pakcoy hidroponik adalah komoditas yang paling efisien dan menguntungkan untuk dijalankan (Rizkia Intan Athifa, 2018).

\section{KESIMPULAN DAN SARAN}

\section{Kesimpulan}

Berdasarkan hasil penelitian terhadap usahatani bayam, maka dapat diambil beberapa kesimpulan sebagai berikut :

1. Dilihat dari teknis penyelenggaraan usahatani bayam yang diterapkan di Desa Abumbun Jaya masih relatif sederhana, ini terlihat dari pengolahan lahan sampai panen.

2. Produksi yang diperoleh dari usahatani bayam di Desa Abumbun Jaya dari 25 petani responden adalah sebesar $1.030,64 \mathrm{Kg} /$ petani dengan harga bayam Rp. $5.500 / \mathrm{kg}$. Sehingga total penerimaan rata-rata adalah Rp. 5.668.520/petani dan Rata-rata pendapatan yang diperoleh sebesar Rp. 2.279.960,10/petani.

3. Untuk usahatani bayam didapat total penerimaan rata-rata adalah 5.668.520/petani dan biaya ekplisit total yang digunakan dalam usahatani bayam adalah rata-rata Rp. 3.388.559,90/petani. Sehingga didapat nilai RCR adalah 1.67.
Nilai RCR usahatani bayam yang lebih besar dari 1 dapat disimpulkan usahatani bayam di Desa Abumbun Jaya layak untuk dijalankan.

\section{Saran}

Untuk meningkatkan keberhasilan usaha tanaman bayam di Desa Abumbun Jaya perlu dilakukan perbaikan sumber daya manusia melalui peningkatan keterampilan petani, perbaikan penyelenggaraan usahatani, penyediaan sarana produksi dan penggunaannya yang sesuai anjuran, penggunaan tenaga kerja yang optimal melaui peningkatan kemampuan petani dalam penyelenggaraan usahatani tanaman bayam. Khusus untuk pemeliharaan tanaman, dimana petani dalam penggunaan pupuk belum sesuai dengan anjuran begitu juga penggunaan benih tidak menggunakan varietas unggul.

\section{DAFTAR PUSTAKA}

Cahyono, 1998. Bayam : Usahatani dan Penanganan Pasca Panen. Kanisius.Yogyakarta.

Dodi Normansyah, Siti Rochaeni, Armaeni Dwi Humaerah , 2014. Analisis Pendapatan Usahatani Sayuran Di kelompok Tani Jaya desa Ciaruteun Ilir Kecamatan cibungbulang Kabupaten Bogor. Jurnal Agribisnis, Vol. 8, No. 1, Juni 2014 Fakultas Sains dan Teknologi UIN Syarif Hidayatullah Jakarta, ISSN : 1979-0058

Dyah Utami, 2017. Prosiding Seminar Nasional Tahunan UNS Volume 1 Nomor 1 Tahun 2017. Semarang

Eka Febrianty , dkk. 2017. Analisis Usahatani Bayam Jepang (Spinacia oleracea Linn) Di Kelompok Tani RST Kecamatan Lembang Kabupaten Bandung. Jurnal Polinela Agribisnis Voume 3 
Nomor 1 Februari 2017, Politeknik Negeri Lampung

Haryati La Kamisi, 2018. Analisis Usahatani Bayam Di Kelurahan Sasa Kecamatan Ternate. Jurnal Ilmu Agribisnis dan Perikanan (AGRIKAN) Volume 6 Nomor 1 UMMU. Ternate

Kartika Kusumawati, dkk, 20165. Pengaruh Konsentrasi dan Frekuensi Limbah Tahu Terhadap Pertumbuhan dan Hasil Bayam Pada Media Pasir Pantai. Jurnal Vegetalika Vo.4 No.2 Tahun 2015 Fakultas Pertanian UGM. Yogyakarta.

Kasmir dan Jakfar, 2008. Studi Kelayakan Agribisnis. Kencana Prenada Media Group. Jakarta.

M. Subana dan Sudrajat, 2005. Dasar Dasar Penelitian Ilmiah.

Nidaul, Syaifudn Nasrun, Irawaty, 2018. Analisis Usahatani Bayam Jurnal Kolaboratif Sains Volume 01 Nomor 1 Tahun 2018. Universitas Muhammadiyah Palu. Palu.

Prasetya, Andika 2009. Analisis Kelayakan dan Optimalisasi Usaha Budidaya Bayam Merah dan Kangkung Hidrofonik Sistem NFT di PT. Joy Farm Depok. Prosiding Seminar Nasional Ilmu Pertanian Fakultas Teknologi Volume 2 Tahun 2009. IPB. Bogor

Rahmat Rukmana, 1994. Bayam. Kanisus. Yogyakarta

Rizkia Intan Athifa , 2018. Analisis Ekonomi Usahatani Sayuran Oriental Dengan Sistem Hidrofonik NFT Tanpa Naungan Greenhouse. Jurnal Agribisnis Terpadu Volume
2 Nomor 2 Mei 2018 Fakultas Pertanian Universitas Sultan Ageng Tirtayasa. Serang Banten

Sibastianus Palaudi , 2015. Analisis Pendapatan Petani Sayuran Di Desa Waiheru Kecamatan Baguala Kota Ambon. Jurnal Agribisnis Kepulauan (AGRILAN) Volume 3 No.1 Februari 2015 Fakultas Pertanian Universitas Pattimura. Maluku

Soekartawi, 2006. Analisis Usahatani. Universitas Indonesia, Jakarta.

Soenoeadji, 2001. Pengantar Ilmu Pertanian Holtikultura. Universitas Gajah Mada,Yogyakarta

Suratiyah, 2006. Ilmu Usahatani, Penebar swadaya. Jakarta

Surya Dharma 2014. Analisa Usahatani Bayam di Desa Hamparan Perak Kecamatan Hamparan Perak Kabupaten Deli Serdang Provinsi Sumatera Utara. Jurnal Wahana Inovasi Volume 3 Volume 1 Januari 2014 Universitas Islam Sumatera Utara ISSN : 2089-8592

Syarifuddin A. Kasim 1995. Pengantar Ekonomi Produksi Pertanian Universitas Lambung Mangkurat Banjarbaru.

Tia Setiawati dkk, 2018. Pertumbuhan Tanaman Bayam Cabut Dengan Aplikasi Pupuk Organik Kescing dan Mulsa Serasah Daun Bambu. Jurnal Ilmu Dasar Vol. 19 No. 1 FMIPA Universitas Jember. Jember

Wiryanta, 2002. Bertanam Bayam, PT Agromedia Pustaka, Jakarta 